\title{
Surgical Complications of Pica Syndrome: About 03 Cases
}

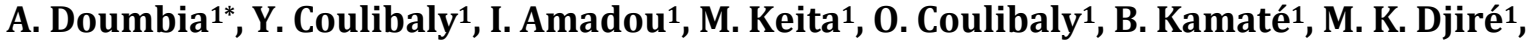 \\ M. Y. Coulibaly¹, S. Camara², H. Diall², B. Maiga'2, D. Konaté2, K. Sacko²
}

${ }^{1}$ Service of Pediatric Surgery, Teaching Hospital Gabriel Toure, Bamako, Mali

${ }^{2}$ Service of General Pediatric, Teaching Hospital Gabriel Toure, Bamako, Mali

Email:^doumbia_aliou@yahoo.com

How to cite this paper: Doumbia, A., Coulibaly, Y., Amadou, I., Keita, M., Coulibaly, O., Kamaté, B., Djiré, M.K., Coulibaly, M.Y., Camara, S., Diall, H., Maiga, B., Konaté, D. and Sacko, K. (2020) Surgical Complications of Pica Syndrome: About 03 Cases. Open Journal of Pediatrics, 10, 159-167.

https://doi.org/10.4236/ojped.2020.101015

Received: December 6, 2019

Accepted: March 3, 2020

Published: March 6, 2020

Copyright $\odot 2020$ by author(s) and Scientific Research Publishing Inc. This work is licensed under the Creative Commons Attribution International License (CC BY 4.0).

http://creativecommons.org/licenses/by/4.0/

\begin{abstract}
The Pica syndrome is an eating disorder characterized by an excessive or abnormal desire to consume a non-nourishing substance which can be relatively harmless, or potentially harmful for the health. It is a rare affection secondary to the accumulation of diverse nature foreign bodies inside the digestive tract and more especially at the stomach level. Gastro-intestinal localization is the most frequent, and can remain long time asymptomatic. Treatment is surgical. We report 3 cases of digestive complication of Pica syndrome. The first one was operated for gastric perforation due to nail (53 nails, a pin and bands of tape recorder cassette ingested), the second one for trichobezoar and the last had a subocclusion by pieces of granite.
\end{abstract}

\section{Keywords}

Pica Syndrome, Complications, Bezoar, Child, Mali

\section{Introduction}

Pica syndrome is an eating disorder mainly observed in people with severe or profound mental deficiency or in those with autism [1]. Its prevalence ranges from $9.2 \%$ to $25.8 \%$, depending on whether Pica's syndrome is confined to the consumption of non-food products, or whether it covers ingestion of food and non-food substances. This prevalence would increase with the severity of intellectual disability [2]. The etiology is not well defined and there is no standard treatment for this syndrome. Patients are treated on a case-by-case basis. Ingestion of non-food substances can be responsible for digestive complications most often requiring surgical management. We report three cases of digestive com- 
plications in Pica syndrome. The informed consents of the children's parents were obtained.

\subsection{Observation 1}

14-year-old female, 3rd of a sibling of 4, followed in psychiatry for mental disorders, admitted for abdominal pain following an ingestion of not digestible foreign bodies.

Symptoms begun 3 weeks before her hospital admission. She was received for diffuse abdominal pain and anorexia, no obstruction to her GI track, nor vomiting. The child received a non-specified traditional treatment that was unsuccessful. She was referred to us in pediatric surgery for better care.

Our clinical examination concludes, a patient with a good consciousness, an altered general body state, conjunctives normal colored, she weighted $34 \mathrm{~kg}$, with a body temperature of $37.5^{\circ} \mathrm{C}$. She was stable on the hemodynamic and respiratory exam. During her abdominal examination: we inspected, an abdomen following well breathing pattern and an epigastrium coving. In abdominal palpation we noticed the presence of skin folds indicating a dehydration and malnutrition. Also, we noticed a diffuse abdominal sensibility, as well as tangible mass at the areas of the left hypochondriac. The rectal bulb was filled with stools in the rectal examination.

Plain abdominal film performed objectified the presence of a heap of nail in the stomach without visualizing a pneumoperitoneum (Figure 1). An abdominal scan (Figure 2) showed mild abundance of intra-abdominal effusion and the presence of nails in the stomach suspecting a gastric perforation. In the biological balance assessment: hemoglobin was at $9 \mathrm{~g} / \mathrm{dl}$, white blood cells at 13,000, plaques at 200,000 , the level of prothrombin at $80 \%$, natrium at $110 \mathrm{mmol} / \mathrm{L}$, potassium at $2 \mathrm{mmol} / \mathrm{L}$, uremia at $0.6 \mathrm{~g} / \mathrm{L}$ and a creatinine at $0.8 \mathrm{mg} / \mathrm{L}$. The diagnosis of peritonitis by gastric perforation was done. The patient has been resuscitated to correct the hydro electrolytic imbalance during 6 hours preceding the surgical intervention. During surgery, we have identified a pre-perforative

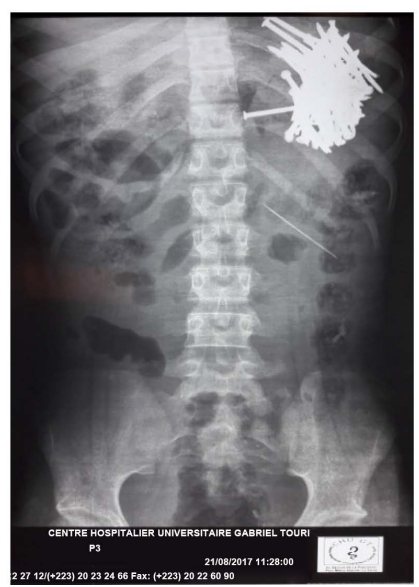

\section{CRANIAL}

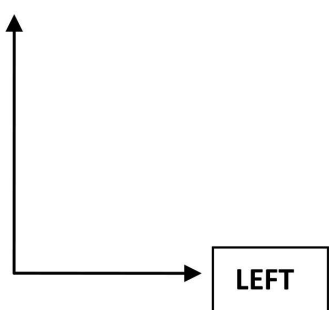

Figure 1. Abdominal plain film. 

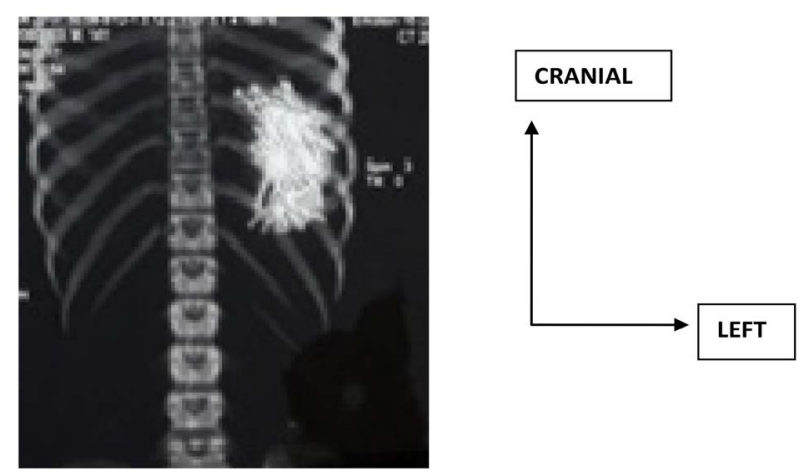

Figure 2. Abdominal CT.

gastric area. We realized a transverse gastrotomy of $4 \mathrm{cms}$ with the soft and progressive extraction of nails (Figure 3). So 53 spikes, a pin and bands of tape recorder cassette (Figure 4) were extracted. The nasogastric probe was left in place. There was no complication following this surgery. The intestinal transit started again at post operative day 1 . The nasogastric probe was removed at D3 and liquid food authorized. She went out of the hospital at D7 with a request of psychiatric evaluation. The surgical outcome was good.

\subsection{Observation 2}

14-year-old girl, without remarkable pathological history, in whom the symptomatology begun 3 months ago, by an atypical diffuse abdominal pains located at the epigastrium, accompanied with late postprandial food vomiting, no obstacle on the GI track, but weight loss and anorexia.

The clinical examination showed an altered general state of the child, well colored conjunctives, her temperature at 37 and her weight at $35 \mathrm{~kg}$. Her abdomen was slightly distended. A farm, mobile and painless enormous mass going from left hypochondria to the epigastrium of approximately $20 \mathrm{cms}$ was palpated. The rectal bulb was empty in the rectal examination. In the biological balance assessment: hemoglobin was at $12 \mathrm{~g} / \mathrm{dL}$, hematocrit at $36.5 \%$, plaques at 265,000 , white blood cells at 13,000, uremia in $0.5 \mathrm{~g} / \mathrm{L}$, creatinine at $6 \mathrm{mg} / \mathrm{L}, \mathrm{CRP}$ at 1 $0 \mathrm{mg} / \mathrm{L}$. Sodium was $125 \mathrm{mmol} / \mathrm{L}$, potassium at $1.5 \mathrm{mmol} / \mathrm{L}$. The rate of prothrombin was $70 \%$ and the activated cephaline time at $30 \mathrm{~s}$.

Plain abdominal film objectified hydro-aeric levels. The abdominal ultrasound objectified a hyper echogenic epigastrium mass with posterior acoustic cone of shadow. The oeso-gastroduodenal transit showed an important gastric distension and a heterogeneous incomplete image molded by the contrast agent interesting all of the stomach (Figure 5). The diagnosis of the trichobezoar was retained. The patient went under surgery. The extraction of the trichobezoar was realized through a wide longitudinal gastrotomy (Figure 6). The nasogastric probe was put. The operating outcomes were simple. The intestinal transit started at day two (2) following the surgery. The nasogastric probe was removed at D3 and liquid food authorized. The patient was sent at the child psychiatrists for a psychiatric evaluation and there was no event postoperativly. 

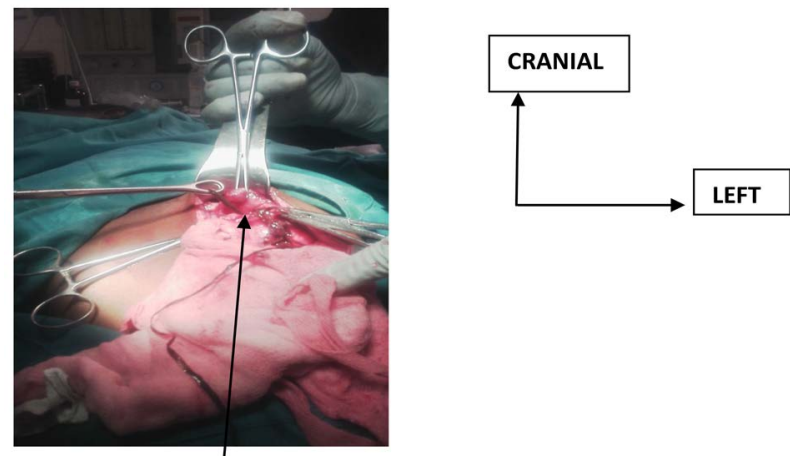

Figure 3. Intra opérative image of spike.

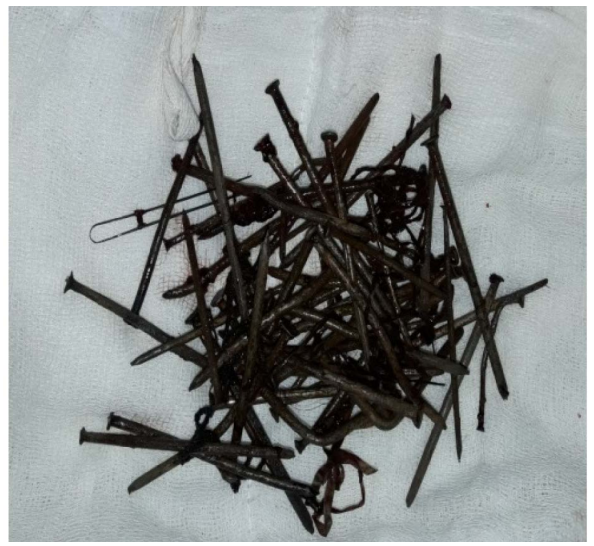

Figure 4. 53 spikes; a pin; bands of recorder cassette extracted.

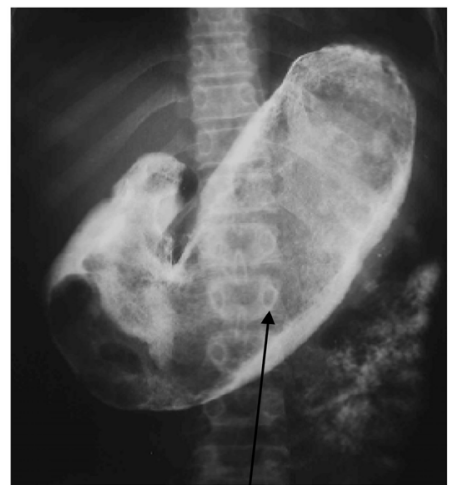

CRANIAL

Figure 5. Upper transit showing a big foreign body.

\subsection{Observation 3}

6-year-old girl, with history of behavioral disorder, admitted for diffuse abdominal pain which goes back to 1 month before her admission with late postprandial vomiting, constipation, change of the general state and anorexia.

In the clinical examination, she presented altered general state, well colored conjunctives. Her temperature at 37.5, her weight at $18 \mathrm{kgs}$. Abdomen was slightly distended with a fixed and painless mass occupying the entire belly. The rectal bulb was filled with pebbles at the rectal examination. 

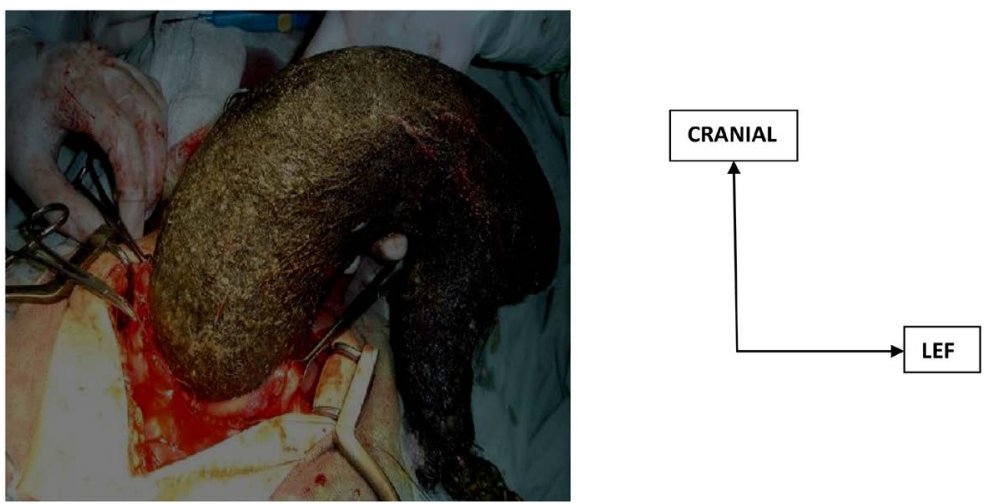

Figure 6. Intra-operative image of the trichobezoar.

Plain abdominal film objectified granite of pebbles occupying all the lumen of the gastronomic-intestinal tract up to the rectum and these pebbles were heaped (Figure 7).

The diagnosis of subocclusion on Pica syndrome was retained.

Evacuating enema with normal saline solution, normacol and of paraffin oil allowed a progressive evacuation of the entire pebbles from the digestive tract and to restore the intestinal transit. The post evacuation outcome was simple. The patient was sent to the child psychiatrist for a psychiatric evaluation.

\section{Discussion}

The Pica syndrome is an eating disorder characterized by an excessive or abnormal desire to consume a non-nourishing substance which can be relatively harmless (ice), or potentially harmful for the health (clay, stones, pieces of metal) as it was the case of our observations.

Many theories about the etiology of Pica syndrome are known [3]: psychological (acquired behavior) [4], environmental (stressful events, a failed social environment) [5] [6], sensory (automatic strengthening) [7] [8] and nutritional deficit (iron and zinc) [9]. Several predispositions or causatives factors can interact in the same individual making those etiologic hypotheses complementary [5] [10]. To reduce or eliminate this behavior disorder, several programs of intervention were developed in mental handicap patients [3]. These approaches lean on nutritional theories (iron, zinc and vitamins supplements) [5] [11], ecological (enrichment of the environment, increasing helps) [6] [10] [12], sensory ("box of pica") [13], and behavioral (differentiated enhancement, physical or mechanics limitation, many others restriction, aversive methods, training in the discrimination) [8] [14] [15].

The bezoar is a term derived from "panzehr", or Arabic «badzehr» which means antidote. It indicates a rare affection secondary to the accumulation of diverse nature foreign bodies inside the digestive tract and more especially at the stomach level [16] [17]. The bezoar type is determined by the nature of accumulated substances (phytobezoar: residues of plant fragments, lactobezoar is made up of curds, observed in infant, trichobezoar formed by a heap of hairs. Other 


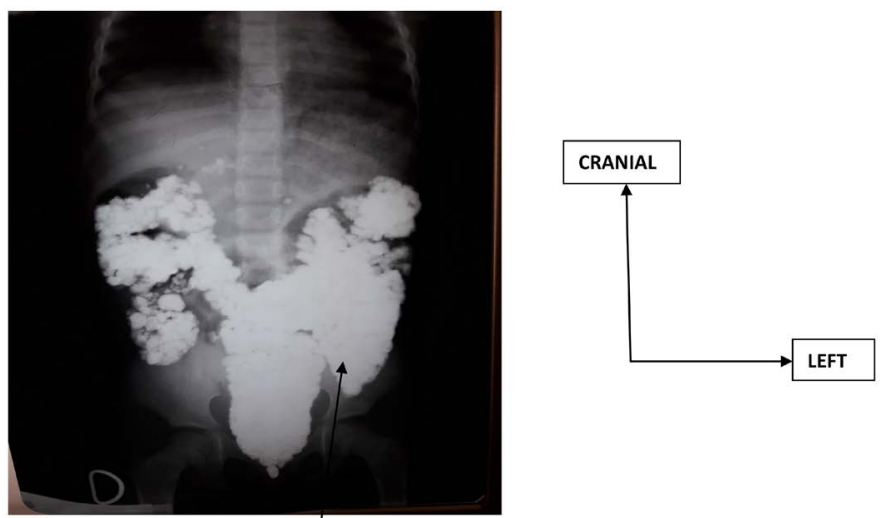

Figure 7. Plain abdominal Film showing pieces of stones.

type of bezoars was described after medicine ingestion modifying the digestive behavior: antacids, cholestyramine called pharmaco bezoar [18] [19].

The trichobezoar is a rare affection in the child $(0.15 \%$ of the gastrointestinal foreign bodies), most of the time, diagnosed late in life with a peak between 10 and 19 years. This affection is more frequent in female (90\% of the cases), and it affects big child in three quarters of the cases [19], as in two of our observations and in the series of Stringel et al. [20].

The first case of bezoar was described in 1779, and until our days, it is observed particularly in children presenting neuropsychiatric disorders mainly the Pica syndrome upon partial gastrectomy [21].

Gastro-intestinal localization is the most frequent, and can remain long time asymptomatic. This may explain diagnosis delay of many years [22] [23]. Exceptionally, it can pass in the small intestine through the pylorus and causes occlusion. Symptomatology is not specific and often dominated by the digestive disorders: epigastrium abdominal pains, nausea and food vomiting which can contain hair [19]. The anorexia and the weight loss can be major and suggestive clinical element. They were noted in our observation during the evolution. Anamnesis has to specify beside functional signs, the presence of contributing factors: diabetes, systemic disease, idiopathic dyspepsia, possible high-fiber diet, and stomach and esophagus surgery. Eating habits disorders must be particularly investigated: titilomanie, trichotillomania, trichophagia, because they are often denied by the patient's relatives [19] [22]. Clinical examination, except in case of complications, seeks for an abdominal mass most of the time located at left hypochondrium and/or of epigastrium, as the case of our two observations. Once the diagnosis of the bezoar is clinically evoked, it is necessary to confirm it by additional examinations. Oeso-gastro-duodenal endoscopy is the technique of choice in small-sized forms located in the stomach. It allows at the same time the diagnosis and the extraction of the foreign body. Other radiological examinations can be especially realized in case of giant trichobezoar. Abdominal ultrasound is indicated in case of palpable abdominal mass in the child. The bezoar is an hyperechogenic mass with a posterior cone of shadow occupying the epigastrium. The upper transit makes the diagnosis of gastric bezoar by showing 
an incomplete mobile intraluminal convex image, and it allows specifying the extension at the duodeno-jejunal level [17] [18]. In our observation three patients have benefited of abdominal plain film, one patient an upper transit, two patients had an abdominal ultrasound and one patient an abdominal scan. Scanning and MRI remain expensive techniques which are not essential for the diagnosis of the bezoar [17] [18]. Plain film had permitted to show the foreign bodies and to make the diagnostic in one case. Abdominal scan and ultrasound were associated in other 2 cases.

On the therapeutic plan, the choice of the technique is discussed according to the teams by taking into account the size of the bezoar. The use of plentiful drinks associated with transit laxatives can be proposed in case of small-sized trichobezoar, as it was the case of one of our observations. In case of failure, the endoscopic extraction can be tried by using laser beam to split up it [17] [24] [25]. In certain cases, the bezoar can be split up mechanically by means of a crowbar with endoscopy and then eliminated by washing. However, there is a risk of gastric or esophageal perforation. Dissolution can be tried using papain, acetylcysteine and cellulose. Besides an incomplete treatment, these methods expose to an important risk of iatrogenic perforation. Therefore, the treatment is often surgical, as it was the case in two of our observations. This allows the extraction of the bezoar and its extensions, to explore all the digestive tract, while knowing that the laparoscopic way is recently proposed as an alternative to laparotomy [17] [26].

Besides certain complications such as intestinal occlusion, an obstruction of the pylorus, gastric perforation as in our observations and some cases of pancreatitis [17] [26] and [27], the evolution remains favorable especially for the child, in addition to psychiatric care basing especially on behavioral therapy, parental education and medical treatment in the patients presenting a trichophagia [16] [17] [28].

\section{Conclusion}

Pica syndrome is a rare affection, which concerns nine times the girl more than the boy. It is associated most of the time with behavioral and the eating disorder (trichotillomanie, trichophagia). Endoscopy allows the extraction according to the location, while the surgery remains the method of choice in case of large-sized bezoar.

\section{Conflicts of Interest}

The authors declare no conflicts of interest regarding the publication of this paper.

\section{References}

[1] Ali, Z. (2001) Pica in People with Intellectual Disability: A Literature Review of Aetiology, Epidemiology and Complications. Journal of Intellectual and Developmental Disability, 26, 205-215. https://doi.org/10.1080/13668250020054486 
[2] Mc Alpine, C. and Singh, N.N. (1986) Pica in Institutionalized Mentally Retarded Persons. The British Journal of Psychiatry, 30, 171-178. https://doi.org/10.1111/j.1365-2788.1986.tb01309.x

[3] Stiegler, L.N. (2005) Understanding Pica Behavior: A Review of Clinical and Education Professionnels. Focus on Autism and Other Developmental Disabilities, 20, 27-38. https://doi.org/10.1177/10883576050200010301

[4] Bicknell, D.J. (1975) Pica: A Childhood Symptom. Butter Worths, London.

[5] Burke, L. and Smith, L. (1999) Treatment of Pica: Considering Least Intrusive Options When Working with Individuals Who Have a Developmental Handicap and Live in a Community Setting. Developmental Disabilities Bulletin, 27, 30-46.

[6] Mace, F.C. and Kinight, D. (1986) Functional Analysis and Treatment of Severe Pica. Journal of Applied Behavior Analysis, 19, 411-416. https://doi.org/10.1901/jaba.1986.19-411

[7] Piazza, C.C., Roane, H.S., Keeney, K.M., Boney, B.R. and Abt, K.A. (2002) Varying Response Effort in the Treatment of Pica Maintained by Automatic Reinforcement. Journal of Applied Behavior Analysis, 35, 233-246.

https://doi.org/10.1901/jaba.2002.35-233

[8] Kern, L., Starosta, K. and Adelman, B.E. (2006) Reducing Pica by Teaching Children to Exchange Inedible Items for Edibles. Behavior Modification, 30, 135-158. https://doi.org/10.1177/0145445505283414

[9] Swift, I., Paquette, D., Davison, K. and Saeed, H. (1999) Pica and Trace Metal Deficiencies in Adults with Developmental Disabilities. The British Journal of Development Disabilities, 45, 111-116. https://doi.org/10.1179/096979599799155948

[10] Piazza, C.C., Fisher, W.W., Hanley, G.P., Le Blanc, L.A., Worsdell, A.S., Lindauer, S.E., et al. (1998) Treatment of Pica through Multiple Analyses of Its Reinforcing Functions. Journal of Applied Behavior Analysis, 31, 165-189. https://doi.org/10.1901/jaba.1998.31-165

[11] Pace, G.M. and Toyer, E.A. (2000) The Effects of a Vitamin Supplement on the Pica of a Child with Severe Mental Retardation. Journal of Applied Behavior Analysis, 33, 619-622. https://doi.org/10.1901/jaba.2000.33-619

[12] Favell, J.E., McGimsey, J.F. and Schell, R.M. (1982) Treatment of Self-Injury by Providing Alternative Sensory Activities. Analysis and Intervention in Developmental Disabilities, 2, 83-104. https://doi.org/10.1016/0270-4684(82)90007-6

[13] Hirsch, N. and Myles, B.S. (1996) The Use of a Pica Box in Reducing Pica Behavior in a Student with Autism. Focus on Autism and Other Developmental Disabilities, 11, 222-225.

[14] Ferreri, S.J., Tamm, L. and Wier, K.G. (2006) Using Food Aversion Todecrease Severe Pica by a Child with Autism. Behavior Modification, 30, 456-471. https://doi.org/10.1177/0145445504272970

[15] Smith-Myles, B., Simpson, R.L. and Hirsch, N.C. (1997) A Review of Literature on Interventions to Reduce Pica in Individuals with Developmental Disabilities. Autism, 1, 77-95. https://doi.org/10.1177/1362361397011008

[16] Debakey, M. and Ochner, A. (1939) Bezoars and Concretions: A Compressive Review of Literature with an Analisis of 303 Collected Cases and Presentation of Eight Additional Cases. Surgery, 4, 934.

[17] Ousadden, A., Mazaz, K., Mellouki, I. and Taleb, K.A. (2004) Le trichobézoard gastrique: Une observation. Annales de Chirurgie, 129, 237-240. 
https://doi.org/10.1016/j.anchir.2004.02.008

[18] Farouk, A., Diffaa, A. and Krati, K. (2013) Le bézoard gastrique: A propos de deux observations et revue de la littérature. Hegel, 3, 124-127.

https://doi.org/10.4267/2042/51159

[19] Hafsa, A.C., Golli, A.M., Mekki, M., et al. (2005) Trichobézoard géant chez l'enfant; Place de l'échographie et du transit oesogastroduodénal. Journal de pédiatrie et de puériculture, 18, 28-32. https://doi.org/10.1016/j.jpp.2005.01.001

[20] Stringel, G., Parker, M. and McCoy, E. (2012) Vinyl Glove Ingestion in Children: A Word of Caution. Journal of Pediatric Surgery, 47, 996-998. https://doi.org/10.1016/j.jpedsurg.2012.01.061

[21] Kakodkar, K. and Schroeder Jr., J.W. (2013) Pediatric Dysphagia. Pediatric Clinics of North America, 60, 969-977. https://doi.org/10.1016/j.pcl.2013.04.010

[22] Kisra, K., Kaddouri, M., Abdelhak, M., Benhamouch, N. and Bahraoui, M. (1998) Trichobézoard. Maroc Médical, 20, 255-258.

[23] Chouraqui, J.-P. and Thomassin, N. (2009) Douleurs abdominales récurrentes, syndrome de l'intestin irritable ou dyspepsie chez l'enfant. Archives de pédiatrie, 16, 855-857. https://doi.org/10.1016/S0929-693X(09)74179-X

[24] Alouni, R., et al. (2005) Trichobézoard gastro-duodeno-jejunal. La presse médicale, 34, 1178-1179. https://doi.org/10.1016/S0755-4982(05)84146-6

[25] Moujahid, M., Ziadi, T. and Ennafae, I. (2011) Un cas de trichobézoard gastrique. Pan African Medical Journal, 9, 1-6. https://doi.org/10.4314/pamj.v9i1.71194

[26] Ellis Hon, K.L., Cheng, J. and Chow, C.M. (2013) Complications of Bezoar in Children: What Is New? Case Reports in Pediatrics, 2013, 1-4. https://doi.org/10.1155/2013/523569

[27] Agarwal, V., Moorthy, K., Jaiprasad, A. and Al-Gailani, M. (2007) Perforated Gastric Trichobézoard: A Case Report. International Journal of Surgery, 3, 124-127.

[28] Bedioui, H., et al. (2005) Les occlusions intestinales aigues sur phytobézoard: Facteurs favorisants et difficultés diagnostiques, A propos de 15 cas. Gastroentérologie clinique et biologique, 32, 596-600. https://doi.org/10.1016/j.gcb.2008.01.045 